\title{
Um Desejo de Aprender: Maquinações de uma Educação Contemporânea
}

\section{A Wish to Learn: Machinations of a Contemporary Education}

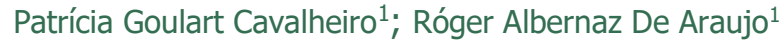

\section{RESUMO}

Este artigo busca, a partir do contexto de uma educação dita contemporânea, perceber como um tensor o tom de um esgotamento do desejo de aprender. Este, que, por sua vez, sobressai-se das relações escolares, mesmo que se tenha, em princípio, condições biológicas, ditas propícias, para uma boa aprendizagem. Neste sentido, em ressonância à estas questões, busca-se mapear deslocamentos e reverberações do conceito de desejo de Gilles Deleuze e Félix Guattari entre a filosofia e a psicanálise, que diferente de uma oposição, constituem-se em um plano de agenciamentos intensivos, na possibilidade de pensar uma educação envolta em diferentes regimes de relações desejantes. Nesta perspectiva, utiliza-se como procedimentos de pesquisa os conceitos de cartografia e de agenciamento, como possibilidade de problematização e potencialização de uma aprendizagem maquinada por um desejo de diferença, que possa inferir no processo de criação implicado no próprio viver, como forma de produzir, novas estéticas singulares de aprendizagem, naquele que aprende, bem como no próprio processo educativo.

Palavras-chave: educação; maquinações; desejo, aprender.

\begin{abstract}
This article searches based on context of an education known as contemporary, to perceive how a tightener the tone an exhaustion of wish to learn. This, in turn, projects the school relations, although it's has in principle biological conditions, known as ideal conditions for a good learning. In this direction, we seeks survey displacements and reverberations the concept of whish based on the notion of Gilles Deleuze and Félix Guattari. This author suggests that between the philosophy and psychoanalysis there is an intensive plan of agencies, with the possibility to think about an education surrounded in different regimes of desiring relations. In this perspective, we use as search procedure the concepts cartography and agency as possibility of problematisation and potentiation machined learning by a wish of difference. The wish of difference that may infer in the creation process, it's involved in the own to live as way of development new singles esthetics of learning. A learning based whom learns, as well as, it based in the itself educational process.
\end{abstract}

Keywords: education; machinations; wish; learn.

\footnotetext{
${ }^{1}$ IFSul - Instituto Federal de Educação, Ciência e Tecnologia Sul-rio-grandense, Pelotas/RS - Brasil.
} 
No contexto da uma educação contemporânea, percebe-se o tom de um esgotamento do desejo de aprender, ainda que se tenham, em princípio, condições biológicas, ditas propícias, para uma boa aprendizagem. Percebe-se que o aprendiz vivencia um momento de inércia, que transborda sensações de esgotamento, no qual parece despotencializado de seu desejo de criar seu próprio modo de aprender e de viver. Tais vivências são percebidas na escola por educadores e educandos, bem como na multiplicidade do campo da educação.

A partir da realidade dos educandos e do suporte das teorias da aprendizagem e do desenvolvimento humano, percebe-se que estes mecanismos não dão conta da complexidade do processo de aprendizagem que se instaura. O aprender vai além de um resultado de uma boa ou uma má aprendizagem, e muitas vezes se atribui o fracasso ao próprio educando, ou ainda, ao contexto familiar, o que encaminha a perda de uma possibilidade de olhar transdisciplinarmente o professor, o aluno, a família e o escopo social. Diante de uma situação diagnosticada como "aluno problema", tende-se, sem saber como dar conta dessa demanda, em muitos casos, atribuir-se a dificuldade de aprendizagem a manifestações emocionais, ou a detenção de processos construtivos do conhecimento, ou mesmo a algum defeito em alguma habilidade específica. Deste modo, faz-se do educando um objeto de aprendizagem, coisificando quem aprende e o que aprende, na tentativa de dar conta da complexidade do processo de aprender.

Para pensar o desejo de aprender faz-se necessário pensar todos os atravessamentos que perpassam e o campo educacional, e pensar a aprendizagem não como um produto, mas como um processo, abrindo a possibilidade de perceber como e porque ela acontece na composição subjetiva do aprendiz.

É notório, na época atual, a sensação de uma intensa produtividade científica, talvez porque nunca se tenha produzido tanto em tantas áreas do conhecimento. O educando vive um momento em que não consegue dar sentido ao conhecimento, este produzido e instituído como verdade absoluta, mecanismo que precipita uma angustiante massificação do conhecimento, num processo estatizante de recognição de memorização. Muitas vezes, não há possibilidade e tempo de elaborar o que se aprende, o que por efeito retira o sentido da aprendizagem

Moran (2003) em "Cabeça bem-feita", aponta que o conhecimento deve ser selecionado a partir dos conhecimentos que produzem sentido, ao passo que Deleuze (2010a) aposta em uma composição pela sensação, pelas forças que capturam e produzem "conceptos, afectos e perceptos"2, produzindo assim novos arranjos subjetivos e estéticos. Neste sentido, a educação constitui-se em uma multiplicidade complexa e desejante, que por meio de uma variação de intensidades, torna-se capaz de produzir mais pela percepção do que pela representação da aprendizagem; mais pela sensação e pela experimentação de novos estados de composição do aprendiz desejante do que a necessidade de representar o que é esse aprendiz.

Nesta perspectiva, a proposta desta pesquisa acontece pelas múltiplas relações e encontros vivenciados na composição destes estudos, na participação no grupo de pesquisa e da própria

\footnotetext{
2 "[...] os percepctos não são percepções, são pacotes de sensações e de relações que sobrevivem àqueles que os vivenciam. Os afectos não são sentimentos, são devires que transbordam aquele que passa por eles." Os conceptos são as intensidades que compõem o processo de criação de um "conceito que comporta as duas outras dimensões as do percepto e do afecto." (DELEUZE, 2013). Ou ainda pode-se encontrar outras referências em "O que é Filosofia" (DELEUZE, 2010, pg. 139-193).
} 
experimentação educativa; espaços de fruição de inquietudes que implicam as questões do desejo dos educandos, em todos os níveis. Afinal, o que envolve o aprender como encontro possível de desejar conhecer outras possibilidades de vir a ser?

Deste modo, tornam a superfície algumas indagações iniciais, que em um primeiro movimento, rabiscam a planificação desta construção. O que há de consciente naquilo que se pensamos? De onde vêm as escolhas? Porque desejamos? O que é o desejo? De algum modo, como premissa básica, pode-se dizer o produto do pensamento é consciente quanto se tem acesso a ele, e inconsciente, quando não. Ou seja, não se tem acesso imediato ao pensamento, e menos se sabe porque se pensa e se deseja, mas isso acontece nas múltiplas relações, por entre fluxos e cortes de um desejo e de um pensamento que, simplesmente, acontece. Por este pressuposto, passa-se a problematizar um segundo movimento: como e por que se produzem os fluxos desejantes no processo de aprender? Quais relações de forças estão envolvidas? Como potencializar o pensamento que questiona sua própria construção? Como se pode criar, neste espaço-tempo de desejo, um processo educativo singular e intersticial?

Neste sentido, em ressonância à estas questões, busca-se mapear os agenciamentos do conceito de desejo de Deleuze e Guattari, entre a Psicanálise e a filosofia, que diferente de uma oposição, se constituem em um plano de agenciamentos intensivos, na possibilidade de pensar uma educação envolta de diferentes regimes de "máquinas desejantes"3, que impulsionam o processo de aprender nesta contemporaneidade.

Nesta perspectiva, deseja-se utilizar como procedimentos de pesquisa a cartografia e o agenciamento. A cartografia, conceito agenciado entre a geografia e a filosofia por Deleuze e Guattari, trata de um procedimento com capacidade de mapear os percursos experimentados e vivenciados no transcorrer de uma pesquisa. Criar e recriar-se, constituindo-se no próprio fazer do pesquisador, numa atitude de abertura, e de estar à espreita a qualquer força dizível ou indizível, que possa perpassar o território de experimentação, na possibilidade de criar efeitos subjetivadores, desvios necessários, ao processo constitutivo de um vir a ser criativo na educação. Então, pesquisa-se! Escreve-se, não a partir do que se entende, e sim, do que afeta e movimenta o pensamento. Um texto não precisa ser compreendido, mas dar-se a compreender, constituir-se em uma experiência que, aparece como meio de descoberta e de um esforço, não para expressar o que sabemos, mas para sentir o que não sabemos (BLANCHOT, 1997).

O conceito de agenciamento movimenta a composição de um "Plano de Imanência"4, e acontece entre/por relações de forças e de pensamentos. Da intensidade dos agenciamentos podem surgir enunciações coletivas: as populações, as multiplicidades, os territórios, os devires, os afetos; isso, em meio aos acontecimentos que perpassam a corporeidade. Entre duas máquinas acopladas acontece uma multiplicidade de agenciamentos, e se uma terceira máquina se produz, que não é por derivação

\footnotetext{
${ }^{3}$ As máquinas desejantes são máquinas binárias [...] sempre uma máquina acoplada a outra. A síntese produtiva, a produção de produção, tem uma forma conectiva: "e", "e depois" ... É que há sempre uma máquina produtora de um fluxo, e uma outra que lhe está conectada, operando um corte, uma extração de fluxo (seio-boca) (DELEUZE; GUATTARI 2010, p. 16).

4 "Os conceitos e o plano, são estritamente correlativos, mas nem por isso devem ser confundidos. [...] Os conceitos são agenciamentos concretos, como configurações de uma máquina, mas o plano é a máquina abstrata cujos agenciamentos são as peças. [...] O plano de imanência não é um conceito pensado nem pensável, mas a imagem do pensamento, a imagem que ele se dá do que significa pensar, fazer uso do pensamento, se orientar no pensamento. [...] o conceito é o começo da filosofia, mas o plano é sua instauração" (DELEUZE, 2010a, p. 45- 46).
} 
da primeira ou da segunda, e sim pela possibilidade do devir em diferença, ou seja, da possibilidade de subjetivações outras, entre as subjetividades e as identidades instituídas.

$\mathrm{Na}$ busca de envolver o conceito de desejo de aprender, percebe-se que este imbricado com o conceito de agenciamento, visto só há desejo agenciado e maquinado, sobre um plano que não preexiste, e que é construído, em um processo contínuo sempre em vias de se fazer, desfazer-se e de refazer-se.

Tais conceitos perpassam o campo da educação propiciando pensar, problematizar e criar outras experiências no campo da educação na contemporaneidade. Experimentações que provoquem pensar uma educação envolta em um processo desejante, em um procedimento de desordenamento necessário à criação da aprendizagem, seja por entre um texto, uma imagem, um pensamento. Buscase percursos possíveis que possam levar o aprendente a produzir em seu processo educativo sua própria autoria, suas marcas, produzindo outras subjetividades. Deste modo, busca-se uma maior intensidade nas relações de aprender, produzindo outros sentidos e significados ao aprender, em uma fuga da repetição e da memorização de um conhecimento longínquo. Busca-se um aprender que possa vir a ser agenciado em acontecimentos de aprendizagem singulares, em uma intensa construção de um viver criativo.

\section{AGENCIAMENTOS DESEJANTES ENTRE A PSICANÁLISE E A FILOSOFIA DA DIFERENÇA}

Isso funciona por toda a parte: às vezes sem parar, outras vezes descontinuamente. Isso respira, isso aquece, isso come. Isso caga, isso fode. Mas que erro ter dito o isso. Há tão somente máquinas em toda a parte, e sem qualquer metáfora: máquinas de máquinas, com seus acoplamentos, suas conexões. Uma máquina órgão é conectada a uma máquina fonte: esta emite um fluxo que a outra corta. (DELEUZE; GUATARRI, 2010, p. 11).

Deleuze e Guatarri, utilizam a seguinte escrita como ponto de entrada no "Anti Édipo: capitalismo e esquizofrenia", o que logo produz em muitos leitores certa estranheza e reverberações múltiplas. Em um agenciamento múltiplo, escrevem esta obra desejante, pois torna-se o puro desejo que se corporifica e continua na escrita dos Mil Platôs - por um pensamento da diferença, da criação de outros modos de existir na contemporaneidade.

O Anti Édipo é a primeira escrita entre Deleuze e Guattari, como Deleuze afirma: "a gente teria se encontrado, teria acontecido isso..." (DELEUZE, 2013). O encontro entre um psicanalista e um filósofo em meio aos acontecimentos de maio de 68. Assim, esta obra surge como um ato de resistência revolucionário de criação, pois resistir é criar outras possibilidades de existir. Para tanto, entranhados pelos muitos autores que os compõem, buscam, principalmente em Nietzsche e Espinosa forças para revolver uma concepção de inconsciente e de desejo inversa ao senso comum e ao pensamento hegemônico dogmático da época, em uma transvaloração do materialismo marxista e do teatro psicanalítico, buscando forças na esquizofrenia enquanto criação, pelo desejo da construção de um novo plano de experimentação.

Ao longo de toda sua produção, Deleuze e Guattari, foram realizando mapeamentos de conceitos, de sensações das mais diversas áreas: ciência, filosofia e arte. Em uma construção de múltiplos roubos, 
e em alguns momentos fazendo "filhos pelas costas" ${ }^{\prime \prime}$, sempre agenciando entre, na busca de produzir novos e intensivos devires: conceptos, perceptos e afectos que são potencializadores da vivacidade da composição construtivista de suas obras.

Os agenciamentos que se compõem na imanência das obras deleuze-guattarianas são da ordem do minoritário, pois o que lançam é o desafio de que cada um produza seus próprios agenciamentos. Deleuze afirmava e, rouba-se sua voz, e diz-se com ele que não queremos que ninguém seja Deleziano, mas que façam como nós, produzam outra coisa, construa-se e se inscreva de acordo com aquilo que the passa ou produza algo.

Por este caminho, pode-se pesquisar na/pela inscrição da potência de forças que produzem um desejo, uma intensidade. Por resistência a aspectos da teoria psicanalítica clássica, Deleuze e Guattari, em um processo de fuga e captura, percorrem um território teórico, que potencializa a criação outra coisa. Pode-se questionar, então, quais forças da teoria psicanalítica violentam o pensamento destes pensadores, ao ponto de irem além e trazer a superfície um inconsciente maquínico? É preciso perceber a obra freudiana como uma obra aberta, não como um sistema, ainda que muitos o façam; mas como fez Freud, colocando a psicanálise na escuta de seu tempo. Freud teria produzido um texto transdiscursivo, que se abre para uma possibilidade infinita de discursos, destacando assim como produção de diferença. Ainda, Foucault, a problematiza como fundadora de discursividade. Assim, é possível entender as ressonâncias potentes nas inscrições discursivas contemporâneas (NÉRI, 2003).

Nesta perspectiva, Deleuze e Guattari, na composição do Anti Édipo, o tempo todo, cria entre os conceitos já instituídos, outros, que produzem ou resgatam as forças intensivas do desejar. Propõem uma desconstrução da concepção psicanalítica do desejo atrelado a falta, configurando-se a teoria fálico-edípica, como uma máquina de captura. Reconhece-se que a grande descoberta da psicanálise foi a da produção desejante, a das produções do inconsciente, mas é o "assentamento do desejo sobre uma cena familiar que faz com que a psicanálise desconheça a psicose, só se reconheça a neurose, e dê da própria neurose uma interpretação que desfigura as forças do inconsciente" (DELEUZE; GUATTARI, 2010). A psicanalise clássica, realiza uma serie de reduções nas teorias e nas práticas analíticas: redução da produção desejante a um sistema de representações ditas inconscientes; redução das fábricas do inconsciente a uma cena de teatro, Édipo, Hamlet; redução dos investimentos sociais da libido aos investimentos familiares; assentamento do desejo sobre coordenadas familiares (DELEUZE; GUATTARI, 2010).

Foucault coloca que foi apenas em meados do século XIX que a sociedade burguesa atribuiu à família a responsabilidade por seus membros, construindo um discurso familiar e moralizante em torno da patologia mental. Ao associar o sofrimento psíquico a um complexo parental, envolvido em culpa e em autopunição, a Psicanálise incorpora-se ao projeto burguês, que mantém o desejo aprisionado no triângulo papai, mamãe e o eu. Ao invés de participar de um movimento de libertação, deixa de fora toda uma vasta dimensão do campo da sexualidade colocada por Freud e logo após, capturada por

\footnotetext{
${ }^{5}$ Ao escrever seus livros Deleuze afirmava: "Eu me imaginava chegando pelas costas de um autor e Ihe fazendo um filho, que seria seu, e no entanto seria monstruoso. Que fosse seu era muito importante, porque o autor precisava efetivamente ter dito tudo aquilo que eu lhe fazia dizer. Mas que o filho fosse monstruoso também representava uma necessidade, porque era preciso passar por toda a espécie de descentramentos, deslizes, quebras, emissões secretas que me deram muito prazer... um indivíduo adquire um verdadeiro nome próprio ao cabo do mais severo exercício de despersonalização, quando se abre às multiplicidades que o atravessam de ponta a ponta, às intensidades que o percorrem" (DELEUZE, 2010a, p.14,15).
} 
tal projeto burguês, reduzindo-a ao que os autores denominam de um "pequeno segredo sujo", familiar, ao invés da fantástica usina de desejo (DELEUZE; GUATTARI, 2010).

Para Deleuze e Guattari o anti-édipo tinha uma "ambição Kantiana, numa espécie de crítica da razão pura no nível do inconsciente", centrando-se em três ênfases:

$1^{\circ} \mathrm{o}$ inconsciente funciona como uma usina e não como teatro. / $2^{\circ} \mathrm{o}$ delírio, ou o romance, é histórico-mundial, e não familiar (deliram-se sobre as raças, as tribos, os continentes, as culturas, as posições sociais); / 30 há exatamente uma história universal, mas é a contingência (como os fluxos, que são objetos da história, passam por códigos primitivos, sobrecodificações despóticas, e descodificações capitalistas que tornam possível uma conjunção de fluxos independentes. (DELEUZE; GUATTARI, 1995, p.10).

Nesse movimento, Deleuze e Guattari inscrevem a sua criação - esquizoanalítica, a partir das forças do capitalismo e da esquizofrenia, no qual, o conceito de máquina é subvertido do capital enquanto produção do neurótico do sistema de produção capitalista tão hegemônico: o mundo da razão, do que é - das verdades, do inconsciente psicanalítico teatral - e buscam forças limite na esquizofrenia: não enquanto identidade nosológica, mas enquanto intensidade criativa, das possibilidades do que pode vir a ser, enquanto criação. Pois "o passeio do esquizofrênico: eis um modelo melhor que o neurótico deitado no divã. Um pouco de ar livre, uma relação com o fora" (DELEUZE; GUATTARI, 2010). Não se diz que o revolucionário seja esquizo, mas afirma-se que há um processo esquizo, de decodificação e de desterritorialização, e que só a atividade revolucionária impede de virar produção esquizofrênica. Nesse sentido, a esquizofrenia torna-se o processo da produção do desejo e das máquinas desejantes (DELEUZE; GUATTARI, 2010).

Nesta proposição, no anti-édipo agenciam-se novas possibilidades entre um inconsciente esquizoanalítico, composto de máquinas desejantes o que tensiona o inconsciente psicanalítico, representante e significante da cultura. Guattari afirma: que "o que buscávamos em comum era um discurso ao mesmo tempo político e psiquiátrico, mas sem reduzir uma à dimensão da outra" (DELEUZE, 2013), instaurando-se um problema, que concerne à relação estreita entre o capitalismo e a psicanálise, de um lado, e os movimentos revolucionários e a esquizoanálise de outro. "Paranóia capitalista e esquizofrenia revolucionária, partindo de suas determinações sociais e políticas. Com um único objetivo, que estas se tornem peças e engrenagens umas das outras" (DELEUZE, 2013), no processo intenso e criativo de viver.

Foucault, na introdução à versão inglesa do Anti-Édipo, que é a própria inscrição do desejo de Deleuze e Guattari, afirma que sem inscrever a palavra ética, este se constitui como um tratado de ética, visto que afirma um modo de pensar e viver numa estilística ética. Nesse intento estariam realizando uma defesa ética e estética do inconsciente como um espaço social e político a ser conquistado (ORLANDI, 1995).

No potente agenciamento de criação com a psicanálise, é central para os autores, o conceito de funcionamento, em resistência ao postulado ontológico da falta. Neste caso, o desejo é sinônimo de máquina, dando início ao termo máquinas desejantes, termo este já utilizado anteriormente por Guattari:

Eu só trabalhava no plano dos conceitos, e, ainda, timidamente. Guattari me falou daquilo a que já chamava as máquinas desejantes, toda uma concepção teórica e prática do inconsciente máquina, inconsciente esquizofrênico. Então tive a impressão 
de que era ele que estava adiantado. Mas com o seu inconsciente-máquina, ele falava ainda em termos de estrutura, de significante, de phallus, etc. Era forçoso, visto dever tanto, a Lacan. Mas eu pensava que isso iria ainda melhor se encontrássemos os conceitos adequados (...) e renunciássemos a noções como estrutura, simbólico ou significante. (DELEUZE, 2013, p.23)

Desejo como máquina que faz emergir o próprio funcionamento, sem significação, em um ponto zero. "Há em toda parte máquinas ...", pois não distinguem homem-natureza, pois já não há nem homem nem natureza, mas unicamente máquinas acopladas, com seus bricoleurs ${ }^{6}$ múltiplos em um processo de produção de produção, que acontece num plano de imanência, no aqui e no agora. Assim, o inconsciente é concebido como fábrica desejante, o que traz à baila que a formulação psicanalítica do inconsciente como teatro edípico não é algo dado, mas que funciona como uma máquina fantástica de repressão do inconsciente.

As máquinas desejantes são máquinas binárias, uma sempre acoplada à outra, "conectivas: "e... e...e", nunca excludentes, sempre produzindo diferenças. No qual, sempre há uma máquina produtora de um fluxo, e uma outra que lhe é conectada, operando um corte, uma extração de fluxo (o seio-boca). Ainda, o fluxo que é desejo, intensidade pura, fluxo a-significante; que não para de produzir o acoplamento de fluxos contínuos e objetos parciais essencialmente fragmentários e fragmentados. "As máquinas nunca são totais, mas parciais, pois a produção criativa se dá nas múltiplas conexões possíveis" (DELEUZE; GUATTARI, 2010). Um exemplo seria o fluxo do aprender que ao ser cortado por outra máquina que é parcial, passa subjetivar-se, materializar-se enquanto saber. O desejo é o que faz correr, flui e é cortado, produzindo uma estética significante de uma produção, num "processo contínuo, simultâneo e múltiplo" (DE ARAUJO, 2015, p 3).

O inconsciente é uma usina, uma metalúrgica operando na máxima potência, que não para de produzir. Funciona como uma fábrica. O desejo se cria, faz-se, expande-se rangendo, na própria corporeidade. E quando o desejo transborda, ele cria, e toda criação acontece no real. Por isso não falta nada ao desejo: todo desejo é produção de realidade.

Tudo funciona ao mesmo tempo nas máquinas desejantes: nos hiatos e rupturas, nas avarias e falhas, nas intermitências e curtos-circuitos, nas distâncias e fragmentações, numa soma que nunca reúne suas partes num todo. Assim não acreditam numa totalidade unificada nem original nem de destinação. Mas percebem apenas totalidades ao lado. E se encontram uma totalidade ao lado das partes, ela é um todo dessas partes, mas que não as totaliza, uma unidade de todas essas partes, mas que não as unifica, e que se junta a elas como uma nova parte composta à parte (DELEUZE; GUATTARI, 2010). Existe em uma visão cultural hegemônica, certa aversão a esse funcionamento que é bem próprio do esquizo, que funciona fragmentado, desintegrado; um homem - natura que remete a natureza como caos que produz mundo, em outros modos de existir que resistem ao "ideal ascético"7. O conceito de objetos parciais buscam em Melaine Klein que afirmam, terem escolhido o exemplo da menos edipianizante dos psicanalistas, para mostrar que esforço ela teve de fazer para

\footnotetext{
6 Termo Francês, designa o aproveitamento de coisas usadas a novos usos.

7 "Num primeiro sentido, o ideal ascético designa o complexo do ressentimento e da má consciência: cruza um com o outro, reforça um pelo outro. Em segundo lugar, exprime o conjunto dos meios pelos quais a doença do ressentimento, 0 sofrimento da má consciência tornam-se vivíveis, organizam-se e se propagam; o sacerdote ascético é, ao mesmo tempo, jardineiro, criador de animais, pastor, médico. Enfim, e este é seu sentido mais profundo, o ideal ascético exprime a vontade que faz as forças reativas triunfarem. [...] As forças reativas nunca preponderariam sem uma vontade que desenvolve as projeções, que organiza as ficções necessárias. O sentido do ideal ascético é portanto o de exprimir a afinidade das forças reativas com o niilismo, exprimir o niilismo como "motor" das forças reativas" (DELEUZE, 1976, p.96).
} 
adequar a produção desejante a Édipo (DELEUZE; GUATTARI, 2010). Nas pulsões parciais não há uma evolução que as faria progredir, com seus objetos, para um todo integrado, bem como a derivação de uma totalidade primitiva. Melaine Klein fez a maravilhosa descoberta dos objetos parciais, mas os pensa como fantasma, e os julga do ponto de vista do consumo, não de uma produção real. Atribui mecanismos de mecanismos de causação (a introjeção e a projeção), de efetuação (gratificação e frustração), de expressão (o bom e o mau), que lhe impõem uma concepção de juízo de valor idealista do objeto parcial. Assim todo processo do objeto parcial, se ocorrer tudo de forma favorável, como as primeiras relações estabelecidas pelo bebê, tende uma integralidade do objeto, do psiquismo, da subjetividade. Conjecturam que Melanie Klein conserva o ponto de vista do todo, talvez para evitar outros atritos, além dos que já tinha com a Associação Psicanalítica Internacional (DELEUZE; GUATTARI, 2010).

Após apresentarem as máquinas desejantes como agenciamento contínuo de fluxos e cortes, eis que Deleuze e Guattari introduzem à noção do corpo sem órgãos, pois nas máquinas desejantes os fluxos de energia estão ainda muito atados, os objetos parciais ainda muito orgânicos. Há um produzir, um produto, uma identidade produto-produzir. É essa identidade que forma um "[..] terceiro termo na série linear: enorme objeto não diferenciado. Tudo para. Tudo se coagula. Depois tudo vai recomeçar" (DELEUZE; GUATTARI, 2010). O corpo sem órgãos é o improdutivo, mas perpetuamente reinjetado na produção, pois é uma característica da síntese conectiva ou produtiva: acoplar a produção a um elemento da anti-produção. Assim, o desejo maquínico tem apenas pontos de entrada e de saída, pois é como um corpo sem órgãos é pura intensidade, forças potentes do que pode vir a ser. "Quando se deseja, já se está sobre o corpo sem órgãos, é o pré-instante da criação, do pensar, da produção" (DE ARAUJO, 2014).

[...] objeto não diferenciado. Tudo para um momento, tudo se coagula.... puro fluido, em estado livre e sem cortes, está em vias de deslizar sobre um corpo pleno. As máquinas desejantes fazem de nós um organismo; mas, no seio dessa produção, em sua própria produção, o corpo sofre por estar assim organizado, por não ter outra organização ou organização nenhuma. "Uma parada incompreensível e certeira" no meio do processo, como terceiro tempo: "Nem boca. Nem língua. Nem dentes. Nem laringe" (...) é o improdutivo, o estéril, o inengendrado, o inconsumível. (...) sem forma e sem figura. Instinto de morte é o seu nome. Porque o desejo deseja também isso, a morte, pois o corpo pleno da morte é seu motor imóvel, assim como deseja a vida, pois os órgãos da vida são a working machine [o funcionamento maquínico]. Não perguntaremos como isso funciona em conjunto: essa questão é já produto de uma abstração. (DELEUZE; GUATTARI, 2010, p. 20)

O conceito de corpo sem órgãos foi inspirado na Teoria das pulsões: Eros - máquina desejante que propicia o acoplamento de fluxos e conexões e, Tânatos - corpo sem órgãos que impede que realizem sínteses macro-molares, funcionando como força disruptiva, possibilitando a criação de novas possibilidades de agenciamentos. Assim, o corpo sem órgãos serve de superfície para o registro de todo o processo de produção do desejo, de modo que as máquinas desejantes parecem emanar dele, num infinito enganchamento de múltiplos pontos de disjunção entre os quais se tece toda uma rede de sínteses novas que quadriculam a superfície (DELEUZE; GUATTARI, 2010).

Deleuze e Guattari apresentam, ainda, uma ressonância entre o corpo sem órgãos e o corpo da histeria, associando o corpo sem órgãos de "Antonin Artaud"8 ao corpo da histeria; a partir desta

\footnotetext{
${ }^{8}$ Antonin Artaud esteve parte de sua vida em manicômios, em decorrência do diagnóstico de esquizofrenia. E como movimento de resistência e de seu talento, escrevia peças de teatro que problematizavam algumas construções e instituições
} 
formulação conectam, ainda, o corpo sem órgãos a uma complexa pragmática do desejo, como forma de combater com o desejo ligado à falta; assim, reúne o desejo com o corpo sem órgãos, como estratégia de dar visibilidade ao acontece no/pelo encontro entre os corpos. Ou seja, Deleuze e Guattari, para se desvencilhar de um plano do corpo ainda contaminado pela imagem e representação, apostam nas intensidades que passam e circulam; concebem o corpo sem órgãos como um "ovo pleno anterior à extensão do organismo e a organização dos órgãos" (...) "ovo intenso que se define por eixos e vetores, gradientes e liminares, tendências dinâmicas com mutação de energia, movimentos cinemáticos" (DELEUZE; GUATTARI, 2010)

Deleuze, mais tarde em um conjunto de entrevistas organizadas por Claire Parnet (1996), no Abecedário, fala sobre o D - desejo:

Queríamos dizer a coisa mais simples do mundo: que até agora vocês falaram abstratamente do desejo, pois extraem um objeto que é, supostamente, objeto de seu desejo [...] Então podem dizer: desejo uma mulher, desejo partir, viajar, desejo isso e aquilo. E nós dizíamos algo realmente simples: vocês nunca desejam alguém ou algo, desejam sempre um conjunto. Não é complicado. Nossa questão era: qual é a natureza das relações entre elementos para que haja desejo, para que eles se tornem desejáveis? Quero dizer, não desejo uma mulher, tenho vergonha de dizer uma coisa dessas [...] Proust disse, e é bonito em Proust: não desejo uma mulher, desejo também uma paisagem envolta nessa mulher [...]O desejo sempre foi, para mim, se procuro o termo abstrato que corresponde a desejo, diria: é construtivismo [...]. Cada vez que alguém diz: desejo isso, quer dizer que ele está construindo um agenciamento, nada mais, o desejo não é nada mais (DELEUZE, 1996,18 -19).

Deseja-se partir de um contexto de vida, de um espaço-tempo, no aqui e agora, na imanência da construção, nunca se deseja algo sozinho, ou um conjunto, mas em um conjunto, pelos agenciamentos e atravessamentos que acontecem. A educação acontece envolta por esse desejo. Assim, qual é o conjunto de forças: livros, currículo, ambiente, relação educador-educando... que possibilitam ou não a inscrição de um desejo, uma aprendizagem. Forças estas que podem ser objetivas e subjetivas, como alguém que fala de um educador que marcou seu processo de aprendizagem, mas que não sabe descrever o que havia de diferencial nesta relação, pois são forças relacionais do campo do sensível, e menos do dizível. Desejar é construir agenciamentos na e com as multiplicidades, com as possibilidades de vir a ser.

\section{AGENCIAMENTOS DESEJANTES DE APRENDER NA CONTEMPORANEIDADE}

Até este ponto se inscreveu parte do processo criativo de Deleuze e Guattari, ao qual, questiona-se quais máquinas parciais foram utilizadas, como se encontraram, e como criaram conceitos; e, em um outro movimento, percorre-se alguns conceitos criados neste singular processo de aprendizagem, que tentam poder problematizar a educação contemporânea.

ditas como verdade e ideal para o homem. Através da experimentação criou o conceito de Corpo sem órgãos. O corpo no estado sem órgãos permite uma reconstrução do exercício da vida cotidiana, pois uma transformação interna acontece. 0 Corpo Sem Órgãos provoca novas formas de interação com o mundo e é um espaço infinito que se desdobra sobre si mesmo, está dentro e fora ao mesmo tempo, se criando, inscrevendo de outras formas possíveis e desejáveis (GUINSBURG; FERNANDES, 1995). 
Deleuze e Guattari resistem aos modelos instituídos de fazer ciência, filosofia e arte, decorrente dos dispositivos de significação hegemônicos, e buscam articular forças criativas nestes territórios. Na tentativa de produzir e criar por entre as partes, não para excluir, e, sim, para ampliar e conhecer o não conhecido, dar voz ao inaudível, e visibilidade ao inexistente, buscam no fora possibilidades de uma diferenciação. Neste intento, buscam forças em teóricos mais subversivos a lógica de pensamento ocidental. Forças como no pensamento literário do "fora" de Blanchot. No entre as forças nietzschiana - reativas: de manter o constituído, a ponta do iceberg das referências, o conhecido, o mundo seguro do neurótico; e ativas: do que não é, mas que pode vir a ser, criação como processo esquizofrenizante, buraco-negro ${ }^{9}$, vozes da desrazão, do imenso desconhecido; pois é no diferencial de forças que se produz energia, produz-se saberes. $O$ ato de pensar tem-se marcado por uma violência de forças de potencial diferente, do fora, que violentam, e colocam o pensamento em um estado de estranheza. Nesse sentido, é mais potente e criador que uma conversa entre amigos, que tem os mesmos referenciais educacionais e vivências; uma conversa com alguém divergente, pois há neste embate, então, uma possibilidade de sacudir o pensamento a pensar e produzir diferença.

E foi o que fizeram Deleuze e Guattari, como possibilidade de poder criar outras experimentações, aprendizagens filosóficas, de um modo micropolítico; uma diferença no que se tinha feito em filosofia até então; o que respinga na atualidade no fazer educacional e tensiona as forças de pensamento a se aliar para produzir minimamente, de forma minoritária, singular, um leve traço de diferença; uma educação desejante.

Deleuze, não pensa em sobrepor a arte, mas em agenciar na composição de um plano de imanência, sem hierarquia, significantes e juízos valorativos, e, sim, com a proposição de um movimento de composição com; em um desejo maquínico de pensar/criar. Neste sentido, nomeia a filosofia, a ciência e a arte como as três "caóides" do pensamento, pois quando engendradas podem violentar o pensamento e colocá-lo na relação com um fora; isso pode desterritorializar o território conhecido e mapeado, colocando-o diante de uma possibilidade de reterritorializar e criar novas roupagens subjetivas (DELEUZE; GUATTARI,2010a).

Deleuze veste à filosofia com uma outra roupagem, para além daquela que se ocupava em refletir coisas, refletir sobe coisas; de algum modo, Deleuze impunha uma necessidade de ir além, como modo de poder vir a criar algo. Em "O que é filosofia?", Deleuze (2010a) esclarece que o processo desejante de aprender se estabelece no plano de imanência, que opera um corte no caos, para a criação de conceitos. Assim, atribuem à filosofia uma necessidade da criação de conceitos, os quais são agenciamentos concretos, configurações de uma máquina, aonde o plano é a máquina abstrata de agenciamentos funcionam na composição de peças. O plano de imanência compõe-se ao mesmo tempo com o que deve e o que pode e o que não pode ser pensado; funciona como um não pensado no próprio pensamento. O plano de imanência, realiza um corte no caos, e desfaz no infinito toda consistência, sem perder o infinito no qual o pensamento mergulha. Diferente da ciência que tenta a todo o momento o referenciar, renunciando ao traçado de ordenadas intensivas de desejo, de movimentos e velocidades infinitas de possíveis contornos variáveis, inscritos sobre o plano. Para tal, se revela a importância da imanência como plano no qual acontecem: desejo, experiência e

\footnotetext{
${ }^{9}$ Havíamos encontrado dois eixos: um de significância e outro de subjetivação. Eram duas semióticas bastantes diferentes, ou mesmo dois estratos. Mas a significância não existe sem um muro branco sobre o qual inscreve seus signos e suas redundâncias. A subjetivação não existe sem um buraco negro onde aloja sua consciência, sua paixão, suas redundâncias. Como só existem semióticas mistas ou como os estratos nunca ocorrem sozinhos, havendo pelo menos dois, não devemos nos surpreender com a montagem de um dispositivo muito especial em seu cruzamento. É entretanto curioso, um rosto: sistema muro branco-buraco negro. (DELEUZE, 2012, p. 35, 36).
} 
aprendizagem (DELEUZE, 2010a). Nesse sentido, a construção de um processo educativo, singular, que tenha a as marcas daquele que aprende, pode ser pelo traçado singular e múltiplo de um plano imanente entre todos os conteúdos ofertados, desejos, sensações, que acontecem em um espaço tempo, e contorne e inscreva, reinscreva seu próprio percurso de aprendizagem.

O desejo de aprender acontece por meio de uma relação de bricoleurs agenciada entre as máquinas de capturas e as máquinas desejantes, o que pode produzir uma diferença subjetiva - um aprender - que se produz em determinado momento. Aprender que acaba sendo capturado e subjetivado, corporificado enquanto saber e conhecimento, e que passa a ser agenciado com outras máquinas, em uma produção desejante de aprender, de fazer, de refazer e de desfazer.

Um imbricamento de máquinas que produzem conexões parciais em suas relações (seio-boca, textosubjetividade, educador-educando). Com isso, tem-se a heterogeneidade de um processo, aonde cada um dos participantes engendra-a por sua própria singularidade, em agenciamentos que ativam múltiplos atravessamentos. Trata-se, não de um desejo de aprender mecânico e orgânico, instituído pela necessidade da falta de um determinado conhecimento, usado para ingressar com sucesso e progresso na matriz social vigente, e, sim, da necessidade de um aprender criativo. Neste entremeio da potência do pensamento maquínico, entre as máquinas capitalistas e esquizofrênicas, problematiza-se os processos desejantes de aprender na educação contemporânea:

O aprender ocupa, na filosofia de Gilles Deleuze, um lugar de destaque. É um ato de adaptação e de criação, um agenciamento complexo, que concerne às condições de possibilidade do próprio pensamento: formação da Idéia e formulação do problema. $\mathrm{O}$ aprender vai além do saber, esposando a vida toda, inteira, em seu curso apaixonado e imprevisível. (SCHÉRER, 2005, p.1).

Aprender é verbo, ação - só acontece se passar e se for engendrado e acionado pelo próprio corpo. Assim, aprender vai além da produção de processos cognitivos e socioeconômicos, e, ainda que transpassado por estes processos, emerge entre eles por sensações que reverberam em afectos e em perceptos de um desejo. No desejo de uma simplicidade do pensamento, pode-se problematizar a formação acadêmica, construindo-se percursos, os quais, muitas vezes, fogem de explicações conceituais e racionais, construindo lugares e paisagens, pelas quais a energia passa, em um jogo de intensidades de forças que atravessam e produzem desejos, experiências e aprendizagens.

Aprender diz respeito essencialmente aos signos. Os signos são objeto de um aprendizado temporal, não de um saber abstrato. Aprender é, de início, considerar uma matéria, um objeto, um ser, como se emitissem signos a serem decifrados, interpretados. Não existe aprendiz que não seja "egiptólogo" de alguma coisa. Alguém só se torna marceneiro tornando-se sensível aos signos da madeira, e médico tornando-se sensível aos signos da doença. A vocação é sempre uma predestinação com relação a signos. Tudo que nos ensina alguma coisa emite signos, todo ato de aprender é uma interpretação de signos ou de hieróglifos. A obra de Proust é baseada não na exposição da memória, mas no aprendizado dos signos (DELEUZE, 2003, p.4).

Os signos tornam efeito de um encontro, e emergem em meio as diferenças; encontros sígnicos que interpelam o pensamento e exercem uma violência tal sobre ele, que torce, sacode, desacomoda e força o pensamento a pensar; signos que se colocam como um problema que exige, mais que uma solução, problematizações. A presença dos signos exige a sua decifração, ele funciona como um acontecimento que se impõe inevitável. Nesse sentido, o desejo de aprender acontece e torna efeito por uma relação de forças, que conectam e agenciam multiplamente todas as experiências vividas no 
aqui e no agora, na produção de um corpo, de um corpo-escrita, de um corpo-saber. A ideia de funcionamento maquínico, torna-se inerente à um aprender desejante; o desejo não é algo dado, e, sim, forçado intensamente a se compor, a processar-se nos/pelos acontecimentos; por entre os campos que perpassam a educação. A aprendizagem não se reduz a uma grade curricular; advém das forças sígnicas subjetivadoras-subjetivadas que afetam o aprendiz, e, que em um segundo movimento produz a estética de uma significação.

O aprender acontece entre um não saber e um saber, em uma passagem viva de um ao outro, de um outro a um; torna-se uma tarefa infinita, aonde se faz necessário a construção do saber; todavia, o não-saber sobre algo abre um percurso de possibilidades de continuar desejando um saber. 0 aprender acontece por um engendramento misturas de pulsões, de desejos e de afectos; antes um rato no labirinto, que aprende com sua errância sem a necessidade achar uma saída, do que aquele sai e põe ênfase, somente em seu saber, declinando deste ponto em diante de potencializar um processo do aprender; e, no processo encontram-se forças encontram-se potências de criar/aprender (DELEUZE, 1988).

Aprender compõe um acontecimento, em uma multiplicidade de heterogeneidades, que efetivam relações de forças incorpóreas, em uma tessitura de possibilidades, com as quais se pode aprender por afectos. O que seduz, atrai e compõe com o corpo - o que se é, e o que se pode vir a ser, passa pelo corpo. Ou seja, uma aprendizagem, por esta perspectiva, talvez não possa ser imposta, dada como pronta e factível de simples apreensão cognitiva, e, sim, potencializada para que possa vir a acontecer no contato duplo com a corporeidade, pela produção de um encontro afectivo, capaz de seduzir e atrair o corpo. Aprender funciona como atitude de "tecer o véu epidérmico de entrelaçamento contínuo, no qual o aprendiz se desfaz ao mesmo tempo em que se constitui em sua teia, o seu território, a sua própria corporaneidade aprendente" (COSTA, 2012).

Os afectos - forças que afetam o corpo e produzem perceptos - criam novas paisagens no pensamento, em uma linha de fuga da imagem dogmática do pensamento; Deleuze aposta numa educação pela afecção criativa, pelas possibilidades de cada um poder criar uma nova geografia do pensamento, potente de abertura para o inusitado caosmótico da vida.

Pensar é deixar-se perder pelo deserto, uma aventura no espaço aberto que dê margem para as criações, o pensamento - expansão turbilhonar acelerada sobre um espaço liso, não submisso à gravidade que rege os corpos - não acontece. Devido a essas potências desterritorializadoras, Deleuze traz imagens apavorantes para as aventuras do pensamento: rajadas, abalos, choques, encontros com movimentos inesperados, forças radicais, velocidades vertiginosas, curvas dilacerantes. O pensamento acontece no preciso momento desse combate de forças, mistura de corpos e efeitos de superfície que os sobrevoam [...] abraçando o caos do impensado (SILVA; CORAZZA; ZORDAN, 2004, p.111-112).

Muitas vezes, pensa-se que se deseja, mas, de certo modo, deseja-se o que querem que se deseje. Ou seja, efetiva-se uma mera reprodução de um pensamento que cumpre a função de um produto; significa-se um desejo introjetado como falta; como necessidade de algo que falta. Em muitos momentos desejam-se coisas, que não são questionadas, até porque o hegemônico pressupõe-se por esta matriz de pensamento pronta e acabada, em nível de consumo imediato. Um desejo que não passa pelo próprio corpo, e do qual o corpo torna-se sujeito; sujeito pelo desejo do outro. Por este caminho, têm-se aprendizes insatisfeitos e esgotados em seu desejo, que intentam alcançar objetivos e metas, os quais lhes fogem, completamente ao contexto que conseguem significar; e um desejo 
corpóreo esvai-se da potência criadora de si. Não que o desejo não seja atravessado pelo desejo do outro, mas que isso seja tomado na condição de encontro necessária à relação, o que talvez, componha uma "máquina parcial" (DELEUZE; GUATTARI, 2010, p. 55). Segundo Deleuze (1996), desejamos em conjunto, mas esse conjunto precisa ser agenciado em um coletivo, como modo possível de uma condição de experimentação na/da própria singularidade.

O desejo acontece por relações de intensidades puras; pelo encontro com forças que podem vir a ser e que, no ponto de efetivação, acontecem pela experimentação e pela vivência destes encontros. Um desejo de experimentação abre possibilidades de potencializar o próprio ato de desejar, ainda em um pré-instante indefinido, sem imagens, delineamentos prévios, e com intensas vibrações, disrupções, imcomposições na possibilidade de inscrições outras de um pensar, de um criar, de um aprender (DELEUZE; GUATTARI, 2010).

O aprender pode se corporificar na/pelas relações de forças estabelecidas e imbricadas pelas máquinas agenciadas, pelas intensidades não nomeadas, as quais fundem-se em um desvelar do corpo-aprendiz. A intensidade e o movimento diferencial criados no processo de aprender têm efeito na intensidade, na velocidade e na potência das forças ativas, que atravessam o campo da experimentação que busca se constituir; com isso, os encontros podem potencializar uma criação, como também, serem capturados sem produzir no aprender possibilidades e marcas estéticas quaisquer.

Talvez, o que toma forma e sobe a superfície, aconteça enquanto corpo-aprendizagem; corpo que aprende alheio a uma mensuração quantitativa qualquer; e, então e, novamente talvez, possa-se perceber como se aprende, numa perspectiva de funcionamento, pelo qual se torna possível marcar "quais são as máquinas desejantes de aprender?" (DELEUZE; GUATTARI, 2013). O que pode um corpo desejante aprender? Têm-se a sensação de que o desejo não deseja ser interpretado; que ele deseja querer criar, poder criar; deseja expandir-se, quiçá rizomaticamente ${ }^{10}$. 0 mundo, a educação, e cada instante possível, cria-se quando acontece a passagem de algo que é na busca de algo que pode vir a ser. Movimento da afirmação da possibilidade de uma educação (re)inventiva de múltiplas possibilidades de acontecer, pelos encontros que cada corpo agenciar, na sua própria experimentação e construção corpórea e transitória de uma aventura do saber.

Uma educação desejante é um desafio que se impõe nesta contemporaneidade; foge a todo o tempo, por linhas de fuga da representação, da recognição e busca a produção de produção, ou seja, a cada instante cria-se e recria-se; busca-se permanecer em devir ${ }^{11}$. Isso provoca um certo estranhamento e um certo desassossego, tanto nos educadores, quanto naqueles que aprendem; o que acontece por força da imersão em um buraco-negro, o qual marca o muro-branco na produção da estética de uma rostidade:

\footnotetext{
${ }^{10} \mathrm{~A}$ arvore já é a imagem do mundo [...] um rizoma como haste subterrânea distingue-se absolutamente das raízes e radículas [...] Não existem pontos ou posições num rizoma, como se encontra numa estrutura, numa árvore, numa raiz [...] ele põe em jogo regime de signos muito diferentes, inclusive estados de não signos [...] ele não é feito de unidades, mas de dimensões, ou antes de direções movediças (DELEUZE, 2011, p.19 -24 - 43).

11 Dizíamos a mesma coisa para os devires: não é um termo que se torna outro, mas cada um encontra o outro, um único devir que não é comum aos dois, já que eles não têm nada a ver um com o outro, mas que está entre os dois, que tem sua própria direção, um bloco de devir, uma evolução a-paralela. É isso a dupla captura, a vespa e a orquídea: sequer algo que estaria em um, ou alguma coisa que estaria no outro, ainda que houvesse uma troca, uma mistura, mas alguma coisa que está entre os dois, fora dos dois, e que corre em outra direção (DELEUZE, 1998, p.6)
} 
[...] Se o rosto é uma política, desfazer o rosto também o é, engajando devires reais, todo um devir clandestino. Desfazer o rosto é o mesmo que atravessar o muro do significante, sair do buraco negro da subjetividade. O programa o slogan da esquizoanálise vem a ser este: procurem seus buracos negros e seus muros brancos, conheçam-nos, conheçam seus rostos, de outro modo vocês não os desfarão, de outro modo não traçarão linhas de fuga (DELEUZE, 2012, p. 64).

Em um estado de espreita aos signos do múltiplo, a educação parece precisar desvencilhar-se do cientificismo dogmático, das matrizes do "muro branco"-"buraco negro", reconstruindo um percurso educativo pela experimentação do risco de um distanciamento, pelo qual se possa deixar a bagagem à beira da estrada, abrir os poros, estar sensível a novidade; e, como diz Corazza (2014), arrancar as cascas de feridas existentes na educação, para ficar mais permeável ao século, as novas manifestações maquínicas. Vislumbrar-se, surpreender-se com novos encontros, outros olhares e experimentações na educação, o que não significa grandes feitos, nem criações macropolíticas, mas movimentos minoritários, intersticiais, na inscrição da artistage ${ }^{12}$ de desejar - aprender nas diferentes geografias educativas.

\section{CONSIDERAÇÕES FINAIS}

O intenso processo construtivo desejante de aprender, para Deleuze e Guattari, desde suas obras, pela própria experimentação criativa entre eles; a filosofia Deleuze e a psicanálise Guattari, numa criação da diferença, em um duplo movimento de repetir e de criar; assim, o agenciamento e a repetição dos vários conceitos, que estão sempre imbricados, acoplados, "e, e, e..." na possibilidade de criar (DELEUZE; GUATTARI, 1995). Um processo que sempre acontece na produção de um plano de agenciamentos heterogêneos, que se torna possível agenciar e ser agenciado pelos atravessamentos pelos quais se tem afectado.

Neste sentido, o processo desejante de aprender se dá sempre em um entremeio: "máquinas binárias"-"máquina desejantes"; desejo pela falta e desejo em excesso de potência; entre o que é representação e o que pode vir a ser, enquanto criação. Em um rizoma, que não tem começo, nem fim, apenas pontos de entrada e de saída, que se constitui no/pelo meio. Pois é o lugar aonde o aprender ganha velocidade (DELEUZE; GUATTARI, 1995).

No livro "Proust e os signos", Deleuze (2003), fala o tempo inteiro de se estar em um entremeio. 0 importante é o que acontece entre, não o que se torna ou aprende, mas o intempestivo movimento de tornar-se; experimentação e vivência. Por um pensar que acontece pela abertura à experimentação da multiplicidade, da diferença; num intermezzo desejante que pode se inscrever em um corpo-saber.

O processo de aprender, através das experimentações e das inscrições de um corpo, aprender a pensar, ou seja, tensionar o pensamento com um fora, com um impensável do pensar, o que o faz entrar em relação com forças outras, que despertam desejos moventes de buscar conhecer outros saberes, que se tiverem potência possível, transformarão o que se sabe, sobre si e sobre o mundo; transformará o que se é. Para Deleuze e Guattari, tudo acontece de forma simultânea, múltipla e num continuum no traçado de um plano de imanência, na construção do processo educativo. Assim,

\footnotetext{
12 [...] chafurdar nos clichês, repetir o mesmo não funciona mais, por termos explodido os cercados e as segmentações territoriais do currículo, só nos resta artistar, não é mesmo? Se não, você para, como educador, se burocratiza, torna-se cansado, triste, [...] culpa os outros... A lei da vida docente vívida, e que vale a pena ser vivida, poderia ser: artistar, de vez em quando, ao menos, para continuar vivo (OLIVEIRA, 2013, p.5).
} 
desejar, criar, pensar e aprender surgem de forma imbricada, de forma fundida, simultânea, no aqui e no agora; em uma construção incessante das subjetividades daquele que se inscreve em uma aprendizagem, na educação, e nos modos de estar no mundo.

Para além de conclusões e de prognósticos, problematizam-se possibilidades de uma inscrição imanente, que possa, quem sabe, vir a precipitar um estrangeirismo na experimentação de forças e de desejos envoltos nestes movimentos, os quais acontecem na passagem de forças que tensionam a educação a pensar; problematizam o que se vive e o que se faz, em transvalorações sucessivas que criam outras imagens, outras inscrições-corpóreas; produzem marcas ínfimas.

Potencializar novas nuances educativas de um aprender desejante, de uma inscrição potente de desejo, aonde o aprendiz produz e é produzido, em um agenciamento contínuo, múltiplo e simultâneo, na busca de uma possibilidade de diferença, de sentido e de movimentos, que possam inferir no processo de criação implicado no próprio viver, produzindo, quiçá, novas estéticas e rostidades naquele que aprende, e no próprio processo educativo. Assim, talvez, possa-se pensar em uma educação ética, que produza "salavancos" e "estilhaços" em meio a uma sociedade de controle.

Por um processo de aprender/viver maquínico, permeado de forças e intensidades criativas, pelas quais, o vir a ser, tem efeito da relação das forças múltiplas que perpassam esta composição. Isso implica nas máquinas que o aprendiz e a própria educação puderem e desejarem agenciar no planômeno ${ }^{13}$. Assim, como ponto de saída e uma nova entrada, problematiza-se: Afinal, quais são suas máquinas desejantes de aprender com/na educação contemporânea?

\section{REFERÊNCIAS}

BLANCHOT, Maurice. O livro por vir. São Paulo: Martins Fontes, 1997.

CORAZZA, Sandra. Áudio Semana Acadêmica da Filosofia: Mato Grosso: Toledo, 2014.

COSTA, Cristiano Bedin da. Corpo em obra: Palimpsestos Arquitetônicos. 2012. Tese (Doutorado) - Universidade Federal do Rio Grande do Sul. Faculdade de Educação. Programa de PósGraduação em Educação, Porto Alegre.

DE ARAUJO, Róger Albernaz. Grupo de pesquisa: GEISSO. Pelotas: 2014.

DE ARAUJO, Róger Albernaz. MÁQUINA-MÉTODO: ensaios de um devir-metodológico. In: BARREIRO, Cristhianny; CASTRO, Beatriz Helena. Narrativas de pesquisa em educação: teoria e prática. Porto Alegre: Observatório da UFRGS, 2014.

DELEUZE, Gilles. Nietzsche e a filosofia. Ed. Rio, 1976.

DELEUZE, Gilles. Diferença e Repetição. Rio de Janeiro: Graal, 1988.

\footnotetext{
13 "Os conceitos e o plano, são estritamente correlativos, mas nem por isso devem ser confundidos. [...] Os conceitos são agenciamentos concretos, como configurações de uma máquina, mas o plano é a máquina abstrata cujos agenciamentos são as peças. [...] O plano de imanência não é um conceito pensado nem pensável, mas a imagem do pensamento, a imagem que ele se dá do que significa pensar, fazer uso do pensamento, se orientar no pensamento. [...] o conceito é o começo da filosofia, mas o plano é sua instauração" (DELEUZE, 2010a, p. 45- 46).
} 
DELEUZE, Gilles; PARNET, Claire. Diálogos. São Paulo: Escuta, 1998.

DELEUZE, Gilles. Proust e os signos. 2.ed. Rio de Janeiro: Forense Universitária, 2003.

DELEUZE, Gilles. A Ilha Deserta - Cinco Proposições Sobre a Psicanálise. Iluminares, 2004.

DELEUZE, Gilles, GUATTARI, Félix. O anti-Édipo: capitalismo e esquizofrenia. São Paulo: 34, 2010.

DELEUZE, Gilles; GUATTARI, Félix. O que é a filosofia? São Paulo: Ed.34, 2010a.

DELEUZE, Gilles. Conversações. Rio de Janeiro: Editora 34, 2013.

DELEUZE, Gilles. O Abecedário. 1996.

DELEUZE, Gilles; GUATTARI, Felix. Mil platôs: capitalismo e esquizofrenia. vol. 1: Rizoma. São Paulo: Ed. 34, 2011.

DELEUZE, Gilles; GUATTARI, Felix. Mil platôs: capitalismo e esquizofrenia. vol. 3: Ano Zero Rostidade. São Paulo: Ed. 34, 2012.

DELEUZE, Gilles; GUATTARI, Felix. Mil platôs: capitalismo e esquizofrenia. vol. 3: Como criar para si um corpo sem órgãos? São Paulo: Ed. 34, 2012.

DELEUZE, Gilles; GUATTARI, Felix. Mil platôs: capitalismo e esquizofrenia. vol. 5. São Paulo: Ed. 34, 1997.

FREUD, S. Edição standard brasileira das obras completas de Sigmund Freud. Rio de Janeiro: Imago, 1969.

GALLINA, Simone. Invenção e aprendizagem em Gilles Deleuze. Tese apresentada ao programa de pós-graduação da Faculdade de Educação da Universidade Estadual de Campinas - SP. Orientador: Silvio Gallo, 2008.

GUINSBURG, J; FERNANDES, Sílvia. Artaud Antonin: Linguagem e Vida. São Paulo: Perspectiva, 1995.

MERLEAU-PONTY, Maurice. Fenomenologia da percepção. São Paulo: Martins Fontes, 2011.

MORIN, Edgar. A Cabeça bem-feita: repensar a reforma, reformar o pensamento. Rio de Janeiro: Bertrand Brasil, 2003.

NÉRI, Regina. Anti-Édipo / psicanálise: um debate atual. Rio de Janeiro. Ágora, vol.6, n.1, pp. 21-43, 2003.

ORLANDI, L. (1995) "Pulsão e campo problemático", in MOURA, Arthur Hipólito de (org.). As pulsões. São Paulo, Escuta.

OLIVEIRA, Thiago. Artistagem, escrileitura e pós-currículo. Bate-papo com Sandra Corazza. Artifícios. Vol. 3, n. 5, 2013.

SCHÉRER, René. Aprender com Deleuze. duc. Soc., Campinas, vol. 26, n. 93, p. 1183-1194, Set./Dez. 2005.

TADEU, Tomaz; CORAZZA, Sandra; ZORDAN, Paola. Linhas de escrita. Belo Horizonte: Autêntica, 2004. 